\title{
Los hermanos erísticos del Eutidemo en las definiciones del Sofista
}

\section{The Eristic Brothers of the Euthydemus in the definitions of the Sophist}

\author{
FRANCISCO VILLAR \\ UNIVERSIDAD DE BUENOS AIRES
}

Recibido: 10/06/2019 Aceptado:03/03/2020

\section{RESUMEN}

En este trabajo defenderé que los erísticos del Eutidemo se dedican a la sofística tal como esta es definida en el Sofista. Propondré que en tanto la quinta y la séptima definición se sirven del

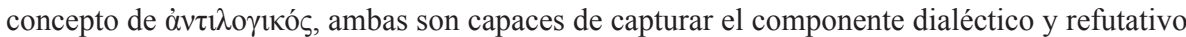
de la práctica erística. Preferiré indentificarlos con la séptima no sólo porque constituye la definición final del sofista, sino también porque esta incluye entre sus determinaciones el empleo engañoso de tal forma de argumentación, rasgo que se ajusta más a la erística que el cobro de dinero, elemento principal de la quinta.

PALABRAS CLAVE

PLATÓN, SOFISTA, ERÍSTICA, DIALÉCTICA, REFUTACIÓN

\begin{abstract}
In this work I will defend that the eristics of the Euthydemus are devoted to sophistry as this is defined in the Sophist. I will propose that the fifth and the seventh definition use the concept of $\dot{\alpha} v \tau \imath \lambda \sigma \gamma ı \kappa o ́ s$ and, therefore, both are able of grasping the dialectical and refutative component of eristics. I will prefer to identify them with the seventh, not only because it constitutes the final definition of the sophist, but also because it includes the deceptive usage of that form of argumentation, a feature that is more in line with eristics than the charging of money, the main element of the fifth.
\end{abstract}


Los DOS ERísticos CON LOS CUALES Sócrates dialoga en el Eutidemo han sido interpretados de manera dispar a lo largo del siglo XX. Una importante tradición de lectura, impulsada inicialmente por Sprague (1972, pp. 294-295) y luego continuada por Kerferd (1981, pp. 53), Nehamas (1989) y Canto (1989, pp. 26-33), considera que Eutidemo y Dionisodoro son parte del movimiento de maestros itinerantes del siglo V a. C. junto a Protágoras, Gorgias, Pródico, etc. Como argumenta Sprague, la decisión de Diels de no incluir a los hermanos entre los presocráticos se debió al prejuicio que circulaba a principios del siglo XX respecto de la omniprescencia de Antístenes como interlocutor de los diálogos platónicos. Sin embargo, su participación en la sofística es para Sprague más que evidente en el Eutidemo, por lo cual abogó por su inclusión.

Esta propuesta ha sido desafiada recientemente por Hitchcock (2000) y Dorion (2000). El primero sostiene que la argumentación dialéctica de tipo refutativa de los erísticos está más cerca de Sócrates tal como es retratado en la obra temprana de Platón que de las prácticas discursivas de los sofistas del siglo V a. C., principalmente de Protágoras, el único de ellos que es vinculado a la erística (D. L. IX.52-53=DK 80, A1). En una línea de lectura cercana a la intuición recogida por Diels, el autor defiende que el mejor lugar para rastrear el origen de la erística es el Sócrates histórico y sus discípulos. Dorion, por su parte, procuró ir más allá de esta sugerencia, identificando al socrático Euclides de Mégara y sus allegados megáricos como las figuras veladas detrás de Eutidemo y Dionisodoro y su específico modo de emplear la refutación. ${ }^{1}$

En un punto intermedio se encuentran algunos comentadores del Eutidemo, como Narcy (1984), Chance (1992) y Sermamoglou-Soulmadi (2014), quienes toman como un dato que los hermanos son sofistas, lo cual, ciertamente, es algo que se afirma al inicio del diálogo, cuando Critón se

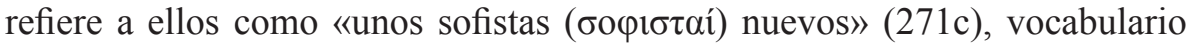

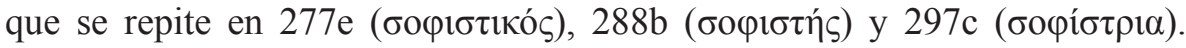
Si bien la datación y la pertenencia intelectual de Eutidemo y Dionisodoro constituye un asunto relevante, y en tal sentido considero que la lectura de Dorion es atendible y probablemente correcta, en este trabajo adoptaré la posición intermedia, puesto que creo que los erísticos son, de hecho, unos sofistas, aunque en un sentido muy preciso de la palabra, a saber, el que Platón construye en el Sofista.

Numerosos expertos han sugerido el punto. Méridier (1931, p. 131) y Hitchcock (2000, p. 62), por ejemplo, los vinculan con la quinta definición

1 La interpretación ya había sido propuesta por Méridier (1931, pp. 128-130) y Hawtrey (1981, pp. 28-30). Dorion, no obstante, ofrece una defensa contundente de ella. Para más razones a favor, Cf. Mársico e Inverso (2012, pp. 42-58) y Gardella (2013). Sobre los ecos antisténicos, Cf. Rappe (2000). 
(225a-226a). Sprague (2000, p. 11) y Dorion (2000, p. 40), por su parte, con la séptima (265a-268d), suscribiendo ambos, además, la opinión de que toda la sección definicional del Sofista parece tenerlos como objetivo. Entre quienes se han dedicado a este último diálogo, Cornford (1935, p. 176) había propuesto a Eutidemo como el depositario de la quinta, aunque dudando de que Platón pretendiera rescatar a alguien en particular con las definiciones, punto en el cual la tradición tendió a seguirlo. Igualmente, Oscanyan (1972) y, más recientemente, Narcy (2013), han insistido en su cercanía con la quinta.

Un equívoco que comparten estas propuestas es el de suponer que en el Sofista hay más de una definición, cuando en verdad sólo la séptima es la correcta y definitiva. En este trabajo defenderé que Eutidemo y Dionisodoro se ajustan al contenido de esta última y solo por ello merecen el calificativo de sofistas. Pero dado que las primeras seis no son ajenas al camino transitado para llegar a ella, mostraré, asimismo, los rasgos de estos personajes que pueden rastrearse en todo el diálogo, principalmente respecto de un punto: la práctica discursiva que se intenta definir y que es finalmente llamada $\varepsilon \dot{\varepsilon} \alpha \nu \tau 10 \pi 010 \lambda о \gamma 1 \kappa \eta ́ ~(268 c)$. Propondré que si la crítica ha oscilado entre la

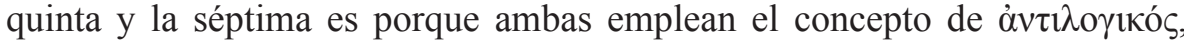
el cual se ajusta al componente dialéctico y refutativo de la actividad de Eutidemo y Dionisodoro.

El trabajo conta de dos partes. En la primera analizo la práctica argumentativa que despliegan los hermanos en las tres demostraciones erísticas del Eutidemo. En la segunda confronto este perfil intelectual de Eutidemo y Dionisodoro con el contenido de las distintas propuestas definicionales del Sofista. Si bien me ocuparé de todas ellas, procurando dar una visión integral del objetivo principal del diálogo, que es definir a la sofística, haré especial énfasis en la quinta y la séptima, para lo cual reconstruiré en detalle sus respectivas divisiones.

El Eutidemo consiste en un relato de Sócrates (275d-304c) enmarcado por un prólogo (271a-275d) y un epílogo (304c-307c). El prólogo narra una conversación con Critón en la que este le pregunta a Sócrates con quiénes había estado conversando el día anterior. Una vez conocidos sus nombres y su calidad de extranjeros, Critón añade lo siguiente: «Son, según parece

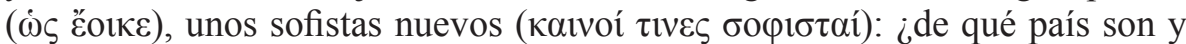

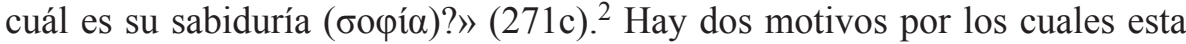

2 Me he servido de los textos fijados por Méridier (1931) y Burnet (1995). Las traducciones siguen en líneas generales a Mársico e Inverso (2012) y Cordero (1988) salvo ligeras modificaciones. 
introducción no permite adjudicarle a los hermanos una pertenencia intectual específica: por un lado, Critón no los conoce y no sabe qué hacen, algo que deja

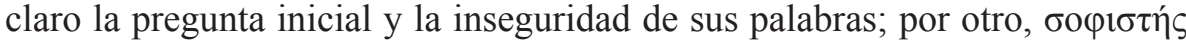
es empleado aquí con un sentido genérico, prácticamente como sinónimo de

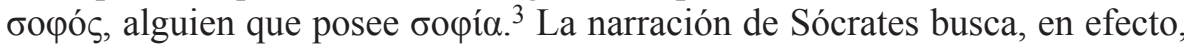
rememorar esa sabiduría.

La descripción (271c-272d) comienza indicando que su sabiduría es asombrosa y ambos son muy sabios, calificativo que merecen por haber

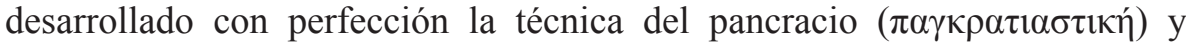
ser, a diferencia de los pancratistas corrientes, unos luchadores completos $(\pi \alpha \mu \mu \alpha ́ \chi 0 \varsigma)$. Su habilidad, ciertamente, no se limita al enfrentamiento corporal:

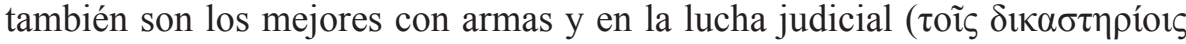
$\mu \alpha ́ \chi \eta)$, tanto discutiendo ( $\alpha(\omega v i ́ \sigma \alpha \sigma \theta \alpha \imath)$ ellos mismos en los tribunales como enseñando a quien les pague a redactar y pronunciar sus discursos.

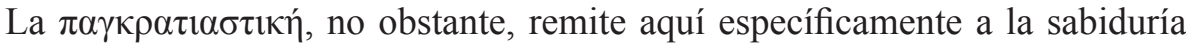

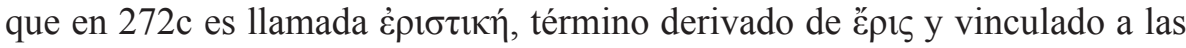

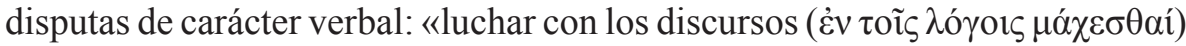

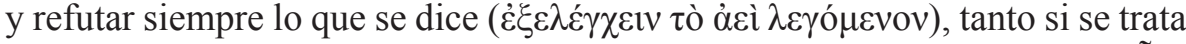

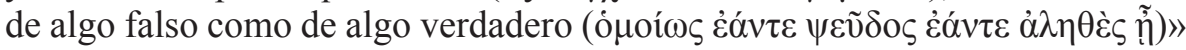
(272b).

Los hermanos, de todos modos, se desentenderán de su dedicación a la lucha corporal, armada y judicial, indicando en $273 \mathrm{~d}$ que a esas actividades ahora las tienen como pasatiempos. De lo que se ocupan en la actualidad es

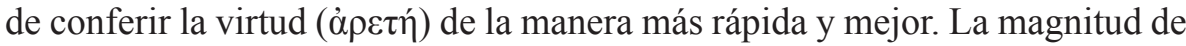
tal promesa despertará la sospecha de Sócrates, que les reclamará que realicen una demostración ( $\dot{\varepsilon} \pi \dot{\delta} \delta \varepsilon 1 \xi 1 \varsigma$ ) de que poseen tal capacidad. En concreto, les solicita que exhorten al joven Clinias a la filosofía ( $\varphi$ i

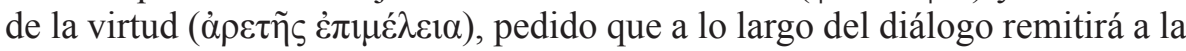
necesidad de formación del muchacho y al deseo de que este se vuelva bueno, mejor y más sabio. El contenido de las tres demostraciones (275d-278e, $283 b-288$ c y 293b-304c) revelará, igualmente, que lejos de entender por

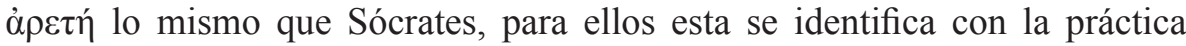

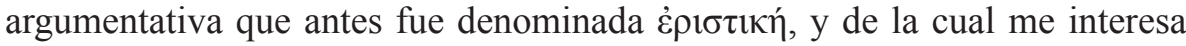
destacar cuatro características.

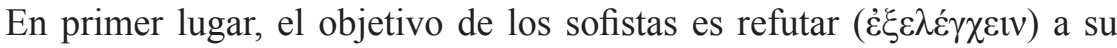
adversario, es decir, construir un argumento que concluya algo contradictorio

3 Sobre бoфıбтńs, Cf. Grote (1850, pp. 479-485), Guthrie (1969, pp. 38-45) y Kerferd (1976), quienes señalan su sinonimia originaria con бoфós, la amplitud de personas con alguna experticia a las cuales era aplicado y su carácter elogioso en oposición a la connotación negativa que adquirirá en el siglo IV a. C. 
o incompatible con una tesis defendida previamente por él. Este propósito, además, es buscado de manera extrema: se jactan de ser capaces de refutar cualquier cosa que se diga. Las dos refutaciones que abren la primera demostración (275d-278e) son una muestra de ello. Clinias es primero obligado a elegir entre si aprenden ( $\mu \alpha v \theta \alpha ́ v \varepsilon \imath v)$ los sabios o los ignorantes. Luego de responder que lo hacen los sabios, Eutidemo elabora un razonamiento que lo contradice, mostrando que, en verdad, aprenden los ignorantes. Pero habiendo aceptado la conclusión, Dionisodoro vuelve a cargar contra el muchacho, probando esta vez que los que aprenden, en realidad, son los sabios. La certeza de la refutación es tal que al inicio del intercambio (275e) Dionisodoro le comenta a Sócrates que no importa qué opción elija Clinias: con cualquiera de las dos será refutado.

En segundo lugar, el procedimiento para elaborar el argumento es dialéctico, entendiendo con ello que se realiza en el marco de una conversación en la cual los roles son claros y están fijados de antemano: el erístico pregunta, $\mathrm{su}$ interlocutor responde (275a-c). Las posiciones a refutar y las premisas necesarias para arribar a la conclusión son siempre el resultado de concesiones a interrogaciones del sofista, las cuales, a su vez, siguen reglas muy estrictas respecto de su contenido: cualquier respuesta que exceda el «sí»» o el «no», o que añada a lo afirmado algún comentario marginal que vaya más allá de las alternativas ofrecidas, es denunciada como un intento de evasión. Tampoco están permitidas las repreguntas ni los pedidos de aclaración (295b-296d), así como la apelación a supuestos ya dejados atrás en la discusión (287b).

En tercer lugar, estas reglas tienen como fin confinar al interrogado a un rol absolutamente pasivo que allana el camino a un rasgo central de la erística: su empleo engañoso del lenguaje. En efecto, las preguntas a las cuales los sofistas exigen una respuesta simple presentan en todos los casos algún tipo de ambigüedad, equívoco o supuesto confuso que hace posible su malinterpretación en pos de la refutación. Los dos argumentos referidos en el primer punto, por ejemplo, hacen uso de la equivocidad del verbo $\mu \alpha v \theta \alpha ́ v \varepsilon i v$, que como Sócrates explica en 278a, puede significar tanto el hecho de adquirir un conocimiento que antes no se poseía como el de servirse de uno ya adquirido, acción que si bien recibe con propiedad el nombre de ovvıćvaı (comprender), también puede ser denominada $\mu \alpha v \theta \alpha ́ v \varepsilon ı v$ (aprender). Lejos de ser un caso aislado, las tres demostraciones erísticas presentan el mismo patrón argumentativo engañoso. ${ }^{4}$

4 La sistematización de los recursos falaces de los erísticos es la tarea de Refutaciones sofisticas. Hawtrey (1981, pp. 2-3) reconoce en el Eutidemo cinco de los trece tipos de falacias analizados por Aristóteles. Sobre el vínculo entre las obras, Cf. Dorion (1995), quien defiende que Aristóteles se dirige contra los mismos sofistas, a los cuales también identifica con los 
Finalmente, los sofistas exhiben una actitud de desdén hacia su interlocutor, al cual buscan refutar solo para dejar en ridículo. A cada refutación de Clinias, por ejemplo, le sigue un coro de seguidores que se ríe de él por no contestar correctamente y encontrarse cada vez más confundido. Esta actitud lúdica está en consonancia con la de sus maestros, la cual acompaña al carácter arrogante de ambos, algo que se vuelve manifiesto a partir de los calificativos que Sócrates utiliza para describir su proceder: «valiente y seguro» (275b), «con una sonrisa» (275e), «con extrema soberbia» (293a), «con mucha ironía» (302b). Este tipo de actitudes despectivas propician un contexto de tensión y malestar que hace reaccionar a los interrogados, los cuales terminan volcándose a la erística, tal como ocurre con Ctesipo en 300b, conversión que marca la victoria de los hermanos y el cumplimiento del objetivo de sus demostraciones.

La atracción que la actividad genera en aquellos que presencian su accionar se vislumbra en la recurrencia a términos vinculados a $\theta \alpha \tilde{} \mu \alpha$ («admiración», «sorpresa», «asombro») para referir a ella, aspecto que incluso provoca que en 302a Sócrates se deje refutar por estar deseoso de escuchar un nuevo argumento. A pesar de ello, Sócrates insistirá en los límites de la práctica al final de cada demostración, calificándola en la primera (278b-d) como un juego ( $\left.\pi \alpha \iota \delta \iota^{\alpha}\right)$ y no como una actividad seria, y comparando a los hermanos, a su vez, con aquellos que se burlan de los que se caen porque alguien les arrebata el asiento. La reiterada petición de que dejen atrás el momento de las risas y comiencen a hablar con seriedad, brindando la exhortación a la filosofía y la virtud que prometieron, no será cumplido nunca desde la perspectiva de Sócrates.

En contrapartida, los dos modelos protrépticos socráticos $(278 \mathrm{e}-283 \mathrm{~b}$ y 288d-293a) presentan otra forma de argumentación. Si bien esta es dialéctica y en tal sentido es similar a la erística, no puede homologarse a ella. Su objetivo, por ejemplo, no es la refutación, sino que, en caso de que esta sea necesaria, lo es en virtud de establecer que un determinado punto que se está debatiendo es inconducente o erróneo. Lo que busca, por el contrario, es construir una posición junto con el interlocutor y no contra él, proceso que se realiza a partir sus aceptaciones y rechazos, acuerdos y desacuerdos. Es posible y deseable, además, que el interrogado adopte un rol activo y coopere en el avance del argumento. Es gracias a tal intercambio que Sócrates y Clinias arriban a

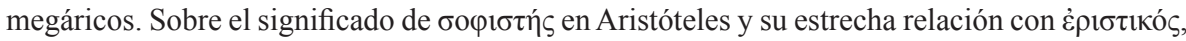
Cf. Classen (1989). 
conclusiones acerca de la necesidad de volverse más sabios y desarrollar el conocimiento, algo en lo cual la erística se revela incapaz durante todo el diálogo. ${ }^{5}$

A través de la confrontación entre la labor de los sofistas y la de Sócrates Platón distingue dos tipos de dialéctica que podrían ser confundidas si quien las observa no atiende a las diferencias en sus fundamentos, métodos y fines. El crítico anónimo de la filosofía del epílogo (304d-305a) es un fiel representante de tal apreciación, en tanto que al condenar en conjunto a todos lo que se dedican a esta actividad, no se preocupa por discernir con cuidado las diferentes modalidades que la misma podría adquirir de acuerdo a quién sea su cultor. ${ }^{6}$ Si bien en el Eutidemo Platón ya avanza en la tarea de desacreditar la argumentación erística, Sócrates aún la considera parte de

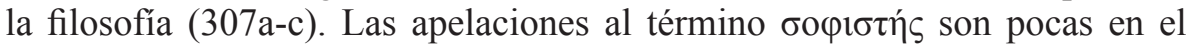
diálogo y están íntimamente ligadas a la cualidad de oopoí de los hermanos. Será en el Sofista, como veremos, donde la erística quedará completamente fuera del terreno filosófico.

La confusión entre las distintas formas que puede adquirir la refutación está presente desde el inicio del Sofista. Teodoro, en efecto, presenta al Extranjero

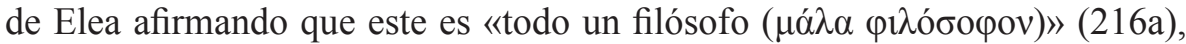
a lo cual Sócrates pregunta si no será que están frente a «un dios refutador

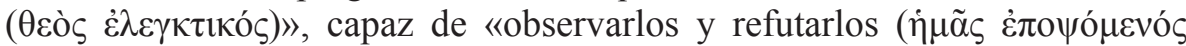

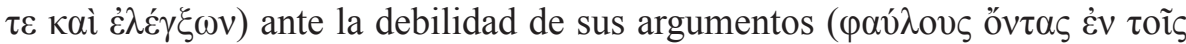

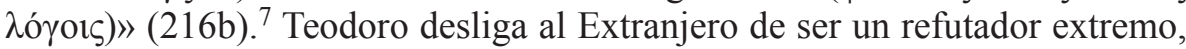
indicando que este es «más mesurado que los expertos en discusiones ( $\tau \tilde{\omega} v$

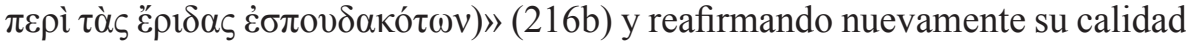
de filósofo. Esta última categoría lleva a Sócrates a introducir la cuestión definicional: dado que el filósofo unas veces tiene aspecto ( $\varphi \alpha v \tau \alpha ́ \zeta \varepsilon \sigma \theta \alpha \imath)$ de político, otras de sofista y otras de alguien loco, su trato con la masa ignorante solo puede dar lugar a un criterio confuso sobre lo que hace. La pregunta

5 Para un análisis del diálogo cooperativo en los diálogos platónicos de transición, Cf. Vigo (2001). Para una confrontación del ideal cooperativo de los protrépticos y el combativo de la erística, Cf. Gill (2000).

6 Varios especialistas (Méridier 1931, pp. 134-138; Hawtrey 1981, pp. 26-27; y Mársico e Inverso 2012, pp. 90-93) consideran que el crítico es Isócrates, quien en Contra los sofistas y Encomio de Helena había atacado a todos los discípulos de Sócrates por dedicarse a la argumentación capciosa.

7 La pregunta podría estar motivada por la patria del Extranjero y su vinculación con Parménides y Zenón en 216a. Sprague (2000) es quizás quien más defiende que la erística posee vínculos con el eleatismo. 
respecto de cómo conciben en la tierra del Extranjero al sofista, al político y al filósofo busca determinar si están ante una, dos o tres figuras y, en caso de ser así, qué tarea le corresponde a cada una.

El Extranjero propone en $218 \mathrm{~b}$ comenzar por el sofista. Teniendo en cuenta la cercanía que en las últimas tres definiciones tendrán los conceptos

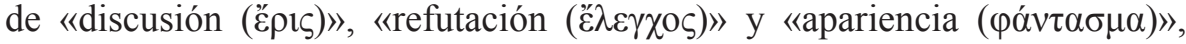
todos ellos cercanos en la conversación introductoria, la elección del sofista se debe al intento de distinguirlo del filósofo. Como adelanté, el inconveniente es que en el proceso de definir al sofista se elaborarán siete definiciones, las cuales, por supuesto, no pueden ser todas correctas. Rickless (2010), en este sentido, ha argumentado que el método de reunión y división hace imposible que la sofística pueda ser hallada en más de un género: en tanto la séptima definición la enmarca en la técnica productiva, eso inhabilita, por ejemplo, que las primeras cinco sean adecuadas, ya que dividen la parte adquisitiva de la técnica. ${ }^{8}$

El autor critica, asimismo, las interpretaciones de Notomi (1999, p. 81), Gill (2006, p. 10) y Sayre (2007, p. 39) que sugieren que las primeras seis definen al sofista a través de sus accidentes, mientras que la séptima captura su esencia. Siendo rigurosos, la única que lo define es esta, quedando para las demás el ser solo intentos fallidos en el proceso de llegar a ella. Si el diálogo ofrece seis tentativas antes de la definición verdadera es porque esta revelará al sofista como un productor de apariencias ( $\varphi \alpha v \tau \alpha ́ \sigma \mu \alpha \tau \alpha)$, sirviendo toda la sección, por tanto, de modelo orientador para arribar a la técnica de la producción. Un indicio a favor de esta interpretación es que el Extranjero y Teeteto se detienen un momento antes de comenzar la definición final para recapitular «de cuántos modos se les apareció ( $\pi \dot{\varepsilon} \varphi \alpha v \tau \alpha \imath)$ el sofista» (231c), aspecto multiforme del personaje que en 231e los hace reflexionar sobre la noción de $\varphi \alpha ́ v \tau \alpha \sigma \mu \alpha$ que retomarán luego.

Si bien la lectura de Rickless es sumamente sólida, hay una cuestión que no desarrolla: la importancia que en la última definición posee el concepto de

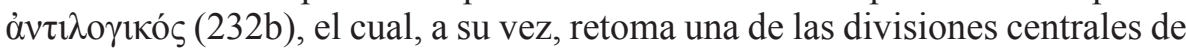
la quinta (225b). En este apartado propondré que aunque ambas definiciones caracterizan una práctica dialéctica con fines refutativos, lo hacen desde perspectivas diferentes: la quinta define al sofista a partir de la adquisición de

8 La sexta divide la técnica según el criterio de separación y combinación (226c). Puesto que para Rickless la división de los géneros se realiza de acuerdo a subclases que son exclusivas y exhaustivas, el «sofista de noble estirpe» (231c), al ser un técnico, debe estar o bien dentro de la productiva o bien de la adquisitiva. El autor propone que debe ser ubicado en la productiva, y en el marco de esta se ocupa de una tarea separativa, mientras que el sofista de la séptima, de una combinativa. Sayre (2006, p. 66) sugiere lo mismo. Cornford (1935, pp. 177-178) considera que la sexta se sirve de un criterio distinto al del resto. 
dinero que este busca gracias a las disputas privadas; la séptima, en cambio, no sólo no tiene al lucro en sus divisiones, sino que, además, realiza un juicio crítico respecto de la argumentación del sofista, denunciando el carácter aparente de su empleo de la contradicción. Este elemento describe mejor la actividad de Eutidemo y Dionisodoro que el cobro de honorarios.

\section{1 LA QUINTA DEFINICIÓN}

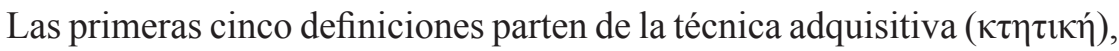
la cual había servido como género superior de la definición del pescador de caña (219a-221b). Lo que define al sofista en estas propuestas es la obtención de dinero. La primera (221c-223b) lo caracteriza como un cazador de jóvenes

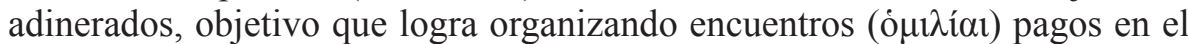

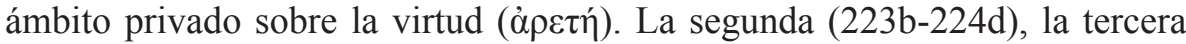
y la cuarta (224d-e) lo definen como un comerciante de conocimientos $(\mu \alpha \theta \eta \dot{\mu} \mu \alpha \alpha)$ y argumentos ( $\lambda o ́ \gamma o r)$ acerca de la misma temática: en la segunda vende de ciudad en ciudad saberes que compra a otros; en la tercera lo hace dentro de su propia comunidad; en la cuarta comercia lo que él mismo elabora. ${ }^{9}$ La quinta (225a-226a), finalmente, coloca al sofista en el género

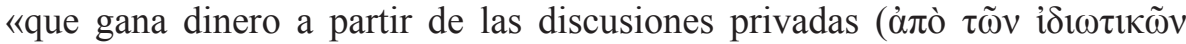

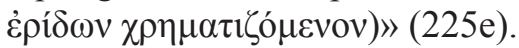

Al menos cuatro elementos vinculan estas definiciones con los sofistas del Eutidemo. Primero, su ánimo de lucro, aspecto que Sócrates resalta en más de una ocasión a lo largo del diálogo, principalmente en Eut. 272a y $304 c$. Segundo, su especial preferencia por los jóvenes de buena posición, ya que si bien en Eut. 304c se indica que aceptan alumnos de cualquier edad, en 272c-d Sócrates enfatiza la predilección de ambos por la juventud, lo cual vuelve esperable que quieran conversar con Clinias y luego busquen convertir a Ctesipo. Tercero, el que tengan a la virtud como objetivo de su educación,

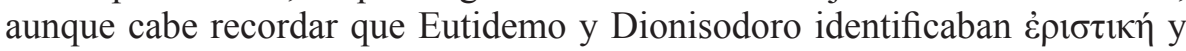

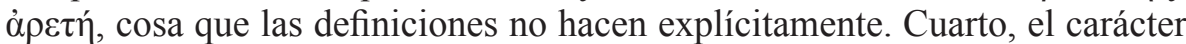
privado de su actividad, rasgo que se desprende no sólo de que su enseñanza se realiza a cambio de un salario, sino también de su distanciamiento de la lucha judicial en Eut. 273d.

Las primeras cuatro definiciones no parecen describir un patrón argumentativo cercano a la erística. El único indicio metodológico de ellas está en la primera, cuando se dice que el sofista «organiza encuentros

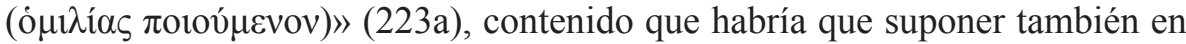
las siguientes. La clave del pasaje está en determinar si el término ó $\mu \imath \lambda i ́ \alpha$

9 A favor de esta lectura de las definiciones dos a cuatro, Cf. Cornford (1935, pp. 174175) y Sayre (2007, p. 63). 
indica alguna modalidad discursiva específica: Cordero (1988, p. 340) traduce «conferencias», quizás por considerar, como Cornford (1935, pp. 173-174),

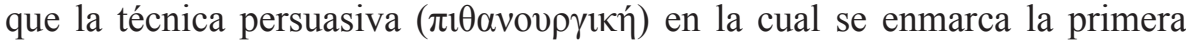
definición implica un ámbito retórico que apela a discurso continuo. Sin embargo, no creo que sea así, por lo cual prefiero traducir ó $\mu \imath \lambda i ́ \alpha$ por lo que propiamente significa: encuentro. ${ }^{10}$ En efecto, al introducir la persuasión en

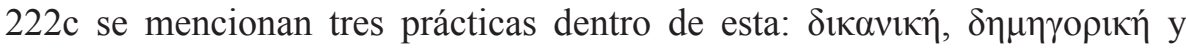

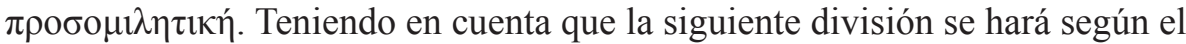
criterio público-privado, las primeras dos harían referencia a los tribunales y la asamblea, y la tercera, que es donde estará la sofística, a una reunión más pequeña.

La quinta (225a-226a) sí es explícita respecto del modo de argumentar del

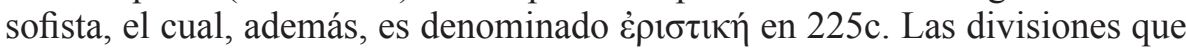
conducen a la erística no sólo describen una práctica discursiva que se asemeja a la de Eutidemo y Dionisodoro sino que también se inscriben en un marco conceptual que recuerda su presentación como luchadores. La definición parte

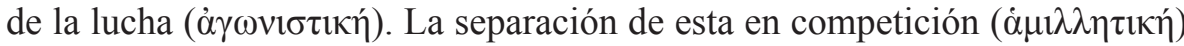

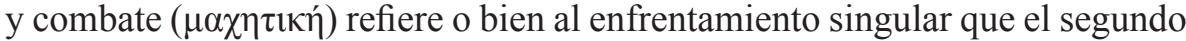
supone o bien a su mayor grado de confrontación. Si el combate se desarrolla «cuerpo a cuerpo $(\sigma \omega ́ \mu \alpha \tau \imath ~ \pi \rho o ̀ \varsigma ~ \sigma \omega ́ \mu \alpha \tau \alpha) »$, le corresponde el nombre de

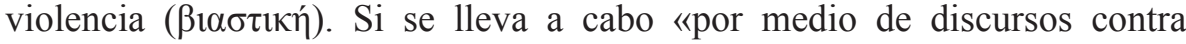

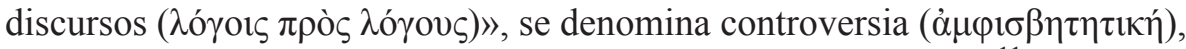
vocablo que da la idea de dos partes que polemizan verbalmente. ${ }^{11}$

Lo relativo a las controversias admite dos formas. El debate judicial

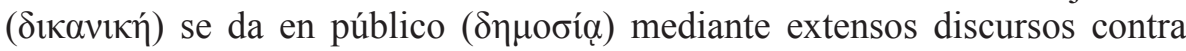

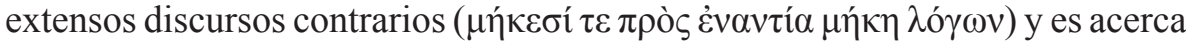

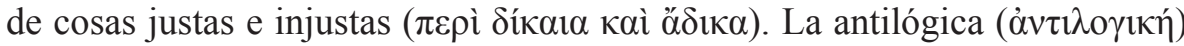
ocurre en el dominio de las cuestiones privadas ( $\dot{\varepsilon} v i \delta$ íorc) y «se divide en

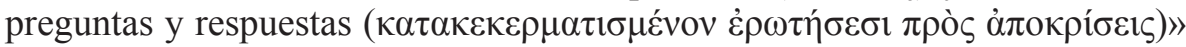
(225b). A la oposición público-privado se añade aquí una característica que

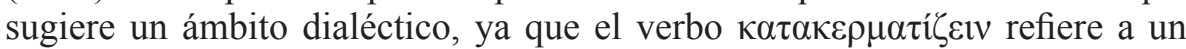
discurso fraccionado, troceado, incluso entrecortado, propio de un desarrollo dialogado de la controversia donde el avance del argumento se logra a partir de

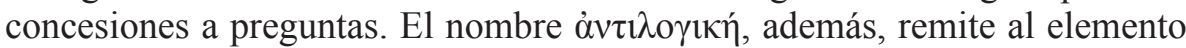
refutativo de la práctica que está siendo definida, la cual, como en el Eutidemo,

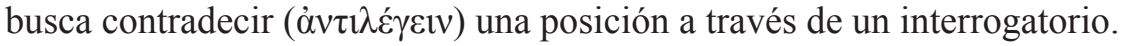

10 Rowe (2015, p. 108) también mantiene cierta indeterminación en ó $\mu \imath \lambda i ́ \alpha$, traduciendo «associating with people». Sobre su campo semántico, vinculado con «tratar» y «reunirse», Cf. Chantraine (1968, p. 798).

11 Me alejo en varios puntos de la traducción de Cordero (1988) en Sofista 225a-226a. 
La penúltima división ahonda en las cuestiones privadas de la controversia antilógica: una parte discurre sobre contratos y se lleva a cabo de modo sensillo

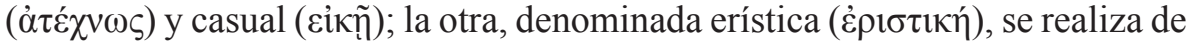
acuerdo con cierta técnica ( $\varepsilon ้ v \tau \varepsilon \chi v o v)$ y versa sobre «las cosas justas e injustas

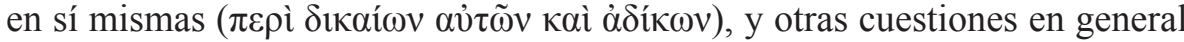

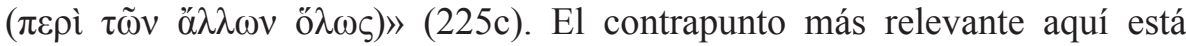
entre la particularidad de las controversias sobre contratos, similar al debate judicial sobre cosas justas e injustas, y la generalidad de la erística, que podría vincularse al tipo de materias que son motivo de debate a lo largo del Eutidemo, todas ellas alejadas de los asuntos materiales o legales de los presentes, tales como el concepto de aprendizaje que recorre la primera demostración y los de ser, no-ser, verdad, falsedad y contradicción de la segunda.

La división final separa en dos la erística: si las discusiones son por el

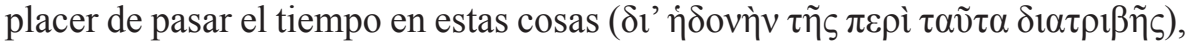
incluso a costa de descuidar los asuntos propios y de que la mayoría de quienes las escuchen las reciban sin placer, su denominación es charlatanería

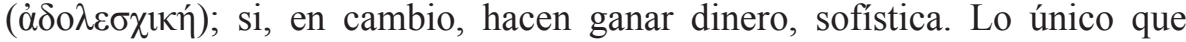
distingue a la charlatanería de la sofística es que una es dilapidadora de dinero

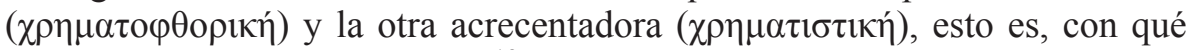
fin emplea cada una la erística. ${ }^{12}$ Dado que el cobro por parte de Eutidemo y Dionisodoro es explícito, en el marco de esta definición son sofistas. Los consejos de Sócrates a ambos en Eut. 303c-304c, no obstante, sugieren que si no cobraran, les podría corresponder el calificativo de charlatanes, principalmente por la advertencia respecto de que sólo ellos y sus seguidores pueden disfrutar con tales refutaciones.

Una característica de esta definición es que no realiza un juicio crítico respecto de la actividad argumentativa del sofista. Exceptuando, por supuesto,

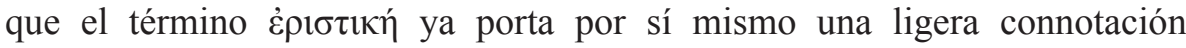
negativa, solo al mencionar la charlatanería esta se vuelve evidente, e incluso por motivos ajenos a sus aspectos discursivos, como puede ser el que esta sea una pérdida total de tiempo de acuerdo al criterio de la gente corriente. Es la alternativa entre la ruina y el lucro personal lo que introduce una nota despectiva en la definición, no una consideración respecto de este particular modo de discutir. Es la séptima definición, como defenderé, la que condena la voluntad contradictora del sofista desde un punto de vista argumentativo.

12 Una muestra de que el cobro de dinero no añade ningún elemento a la actividad discursiva del sofista está en cómo se enuncia la quinta definición en la recapitulación posterior:

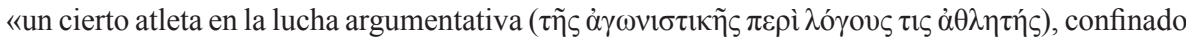

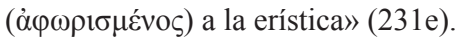




\section{2 LA SÉPTIMA DEFINICIÓN}

El Extranjero comienza la séptima definición señalando que algo parece haber revelado al sofista de forma destacada $(\mu \alpha \dot{\alpha} \lambda \iota \tau \tau)$, recordando para ello que antes, en $225 \mathrm{~b}$, afirmaron que «era, en cierto modo, un contradictor

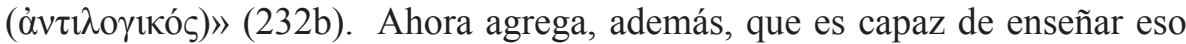

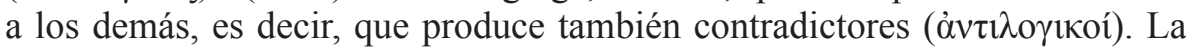
búsqueda de los contenidos que contradice hace que la investigación tome distancia por un momento del ámbito estricto de la antilógica, ya que, en tanto su capacidad de contradecir abarca los asuntos privados, los públicos e incluso los de los artesanos, su tarea se revela como una «controversia acerca

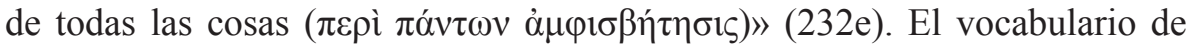
la contradicción, de todos modos, será retomado inmediatamente y seguirá permeando la conversación.

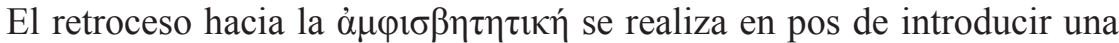
cuestión crucial para criticar la argumentación del sofista: su técnica no se limita a un contenido, sino que pretende contradecirlo todo. Dado que nadie es capaz de tener conocimiento de todo y el sofista afirma ser capaz de contradecir al que sabe, es evidente que debe dar la impresión de que sabe aquello acerca de lo cual contradice, poseyendo, por tanto, una ciencia

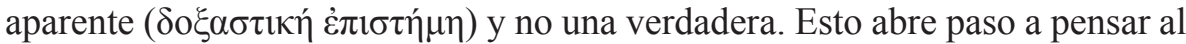
sofista como un imitador y, por tanto, en el marco de la técnica productiva y no adquisitiva, ya que la fórmula final no incluye el cobro de dinero: su fin último, enmarcado en un aparato conceptual que da cuenta de su carácter engañoso,

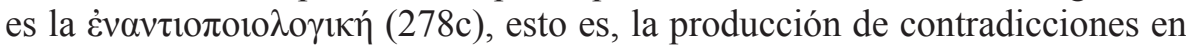
el lenguaje.

Dado que esta definición se inscribe en la antilógica, hay que suponer en ella un modo de proceder dialéctico. Lo que añade respecto de la quinta es su radicalidad, rasgo que encuentra una instanciación perfecta en la intención refutativa total de Eutidemo y Dionisodoro. Asimismo, el que el sofista sea presentado como capaz de contradecir cualquier cuestión y a cualquier oponente, incluso al que sabe, hace que el Extranjero y Teeteto le apliquen dos calificativos con reminiscencias al Eutidemo. Por un lado, si el sofista es realmente capaz de hacer lo que promete, o al menos parecer que lo hace, el poder de su experticia constituye un $\theta \alpha \tilde{u} \mu \alpha$ (233a), esto es, algo digno de asombro. Por otro lado, al revelar en $233 \mathrm{~d}$ al sofista como capaz de producir todas las cosas por medio de sus contradicciones, Teeteto juzgará a su técnica como un juego ( $\pi \alpha 1 \delta$ ió), elemento que junto al anterior hará que la conversación se dirija hacia la imitación.

La breve descripción del sofista en 239b-242b refuerza los paralelos con el Eutidemo, principalmente respecto de dos puntos: el carácter interrogativo 
de su práctica y la actitud que este adopta ante su interlocutor. El Extranjero remite allí a la evasiva del sofista frente a la acusación de que posee una técnica simulativa: cuando lo acorralen afirmando que es un fabricante de

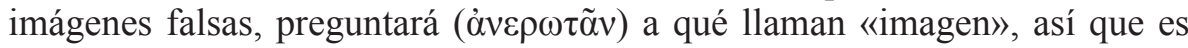
necesario hallar una respuesta a sus preguntas. Ante la ingenua propuesta de Teeteto, que se limita a señalar la existencia de reflejos en el agua y en los espejos, el Extranjero insistirá que con tal respuesta lo único que logrará será que el sofista se ria de él. Hará de cuenta que tiene los ojos cerrados y, además, pretenderá ignorar qué son los espejos, la vista y el agua, y «sólo preguntará

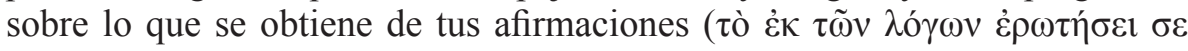
uóvov)» (240a).

Si bien estos rasgos de la sofística son centrales, la conversación se distanciará de ellos durante la digresión sobre el problema de lo falso (242c-264c), ya que esta sección busca fundamentar la posibilidad de la simulación en general y no una práctica argumentativa concreta. Esta volverá a aparecer recién cuando se reformule la séptima definición en 264c-268d, y más precisamente, en su última división. Dentro de la técnica productiva ( $\pi$ oıๆ $\imath \kappa \eta ́)$, una parte hace cosas reales; la otra, imágenes de las cosas ( $\varepsilon i \delta \omega \lambda$ o se divide, a su vez, en figurativa (

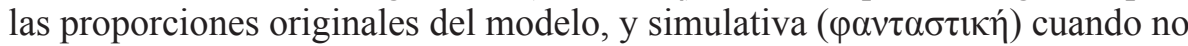
lo hace, sino que produce una mera apariencia $(\varphi \alpha ́ v \tau \alpha \sigma \mu \alpha)$, algo que parece

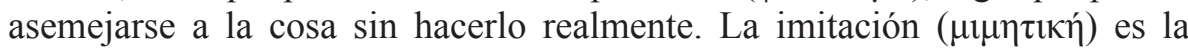
parte de la simulación que emplea el cuerpo para lograr esa falsa apariencia.

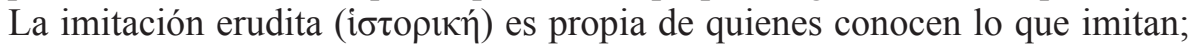

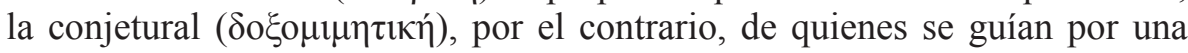
opinión, algo que algunos hacen a causa de su ingenuidad, mientras que otros, los imitadores irónicos ( $\varepsilon i \rho \omega v i \kappa \eta ́)$, hacen adrede. ${ }^{13}$

La división final separa en dos la tarea de este último tipo de imitador:

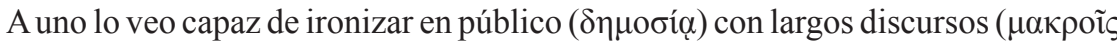

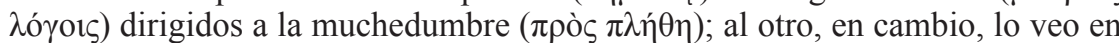

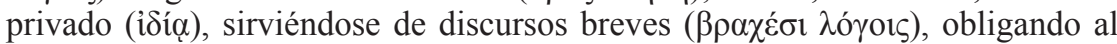

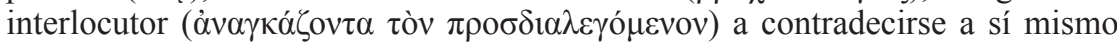

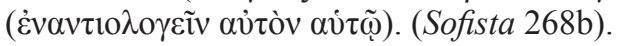

13 La ironía radica en el conflicto que se da entre la conciencia que el sofista tiene de su ignorancia y la declaración de que conoce aquello acerca de lo cual contradice. Sobre esta división, Cf. Notomi (1999, pp. 288-292), quien remite a la descripción de la actitud de Dionisodoro como

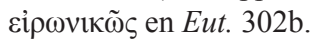




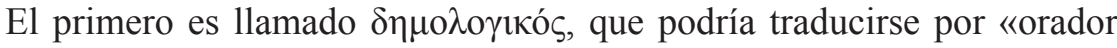
popular» en virtud del carácter público de su extenso discurso y su intención de dirigirlo a un auditorio. El sofista está volcado al ámbito privado y se opone a un único adversario.

Las palabras que describen la argumentación sofística la colocan dentro de la práctica antilógica. El enfrentado al sofista, en efecto, es referido a partir del término $\pi \rho \circ \sigma \delta 1 \alpha \lambda \varepsilon \dot{\gamma} \sigma \mu \alpha$, el cual debe remitir a un ámbito de conversación donde es necesario que este asuma el rol de interrogado, principalmente por dos razones: por un lado, si al dividir la controversia en la quinta definición (225b) la extensión de los discursos de carácter publico se oponía a la fragmentación en preguntas y respuestas en privado, la contraposición entre discursos públicos extensos y breves privados de esta definición debería hacer referencia a la misma oposición; por otro lado, el único modo en que el sofista podría forzar a que su interlocutor diga algo en contra de sus afirmaciones sin ofrecer él mismo la contradicción es hacérselo admitir a través de un interrogatorio.

El Sofista incluye un ejemplo de esto: la demostración de que nadie es capaz de «afirmar que se pueden decir y pensar falsedades [...] sin incurrir

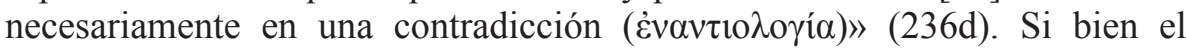
argumento no lo construye el sofista por sí mismo, porque no hay ninguno presente, el Extranjero lo desarrolla como si fuera uno, empleando a Teeteto como interlocutor. La concepción absoluta del no-ser que el sofista imaginario utiliza para oponerse a la existencia de la falsedad es lo que hace de su argumentación un engaño asimilable a la definición: dado que la falsedad es posible, y «lo que no es», en tanto diferencia y en sentido relativo, es, al servirse de artilugios dialécticos para defender lo contrario y hacer que Teeteto admita una tesis aparentemente verdadera, el sofista lo está contradiciendo solo de modo aparente. ${ }^{14}$

Eutidemo y Dionisodoro son portavoces de este mismo posicionamiento en la segunda demostración erística (Eut. 283c-288b). Más aún, considero que la sección 237b-242a del Sofista tiene una instanciación perfecta en esa demostración, la cual puede ser leída como la escenificación de tales razonamientos: si en Sofista el Extranjero argumenta desde el punto de vista que adoptaría un sofista, mostrando cómo este se resistirá a la existencia de la falsedad al ser acusado de producir meras apariencias, en el Eutidemo son directamente dos sofistas los que reaccionan contra la acusación, ya que sus refutaciones sobre el tema se introducen cuando Ctesipo los censura por mentir respecto de que los presentes quieren matar a Clinias (Eut. 238e). La

14 Para el carácter aparente de la contradicción del sofista, Cf. especialmente Notomi (1999, pp. 292-296). 
apelación a una noción existencial del no-ser y el paralelo que se establece entre esta y lo falso coinciden, además, en el tratamiento del problema en ambos diálogos. ${ }^{15}$

Si bien la quinta definición rescata el componente argumentativo de la labor sofística, el elemento condenatorio de esta descansa completamente en encerrar al erístico en la alternativa, incómoda pero superficial, de la charlatanería y el lucro. La séptima ataca a la actividad del sofista en un aspecto fundamental de ella, denunciando que este no hace genuinamente lo que dice hacer: contradecir sobre cualquier materia a su adversario y, por tanto, ser sabio respecto de tales cosas. Aunque en Sofista 233b y 234a se indica que el sofista puede solicitar dinero a cambio de su capacidad de producir contradictores, rasgo que comparte con Eutidemo y Dionisodoro, la adquisición de dinero está ausente de la definición final. Es el empleo engañoso e impostado de la dialéctica lo que, en sentido estricto, define a la sofística en el Sofista.

\section{III}

Desde el inicio del Sofista está presente la confusión entre sofística y filosofía a partir de su entrelazamiento con los conceptos de discusión y refutación. El trabajado contraste entre las últimas tres definiciones es lo que permite superar esa aparente indistinción, trayendo precisión conceptual a algo que el Eutidemo realiza en escena, esto es, a partir de la confrontación efectiva entre ellas. A modo de conclusión, me gustaría destacar brevemente algunos elementos de la sexta que permiten integrar en una interpretación general del diálogo la confrontación entre la quinta y la séptima.

La sexta definición (226a-231c) describe un procedimiento argumentativo que es el único que merece ser llamado «refutación ("̌̉ $\lambda \varepsilon \gamma \chi 0 \varsigma)$ ) por parte del

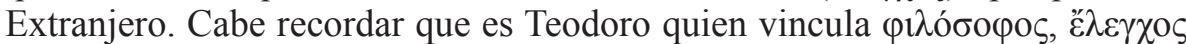
y ěpı con un tono ligeramente peyorativo en 216a-c. Pero la definición del sofista como un purificador de almas a través de la refutación está muy lejos de ser negativa. El Extranjero incluso duda sobre si tal personaje merece el nombre de sofista, prefiriendo para su técnica la famosa fórmula "sofística de

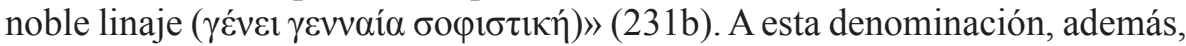
cede sólo porque Teeteto insiste en que este se parece al sofista, impresión

15 Un análisis del problema de la falsedad en Eutidemo y Sofista excede los límites de este trabajo. Sobre la temática en la obra de Platón en general, incluido el Eutidemo y el Sofista, Cf. Crombie (1963, pp. 486-498) y Denyer (1991). Para una defensa de que las refutaciones de la segunda demostración del Eutidemo apelan a los mismos supuestos que el Sofista, Cf. Notomi (1999, pp. 179-189) y Marcos (2000). 
comprensible, ya que, como el sofista, el refutador también se dedica a una forma de antilógica. Obsérvese cómo se caracteriza la actividad refutativa:

Interrogan $(\delta 1 \varepsilon \rho \omega \tau \tilde{\omega} \sigma \mathrm{v})$ primero sobre lo que alguien cree que dice, cuando en

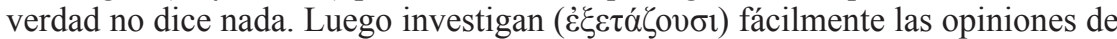
los así desorientados, y después de recoger los argumentos, los confrontan entre

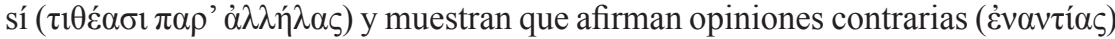

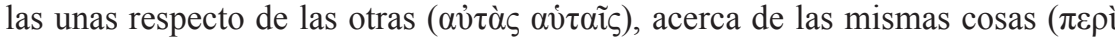

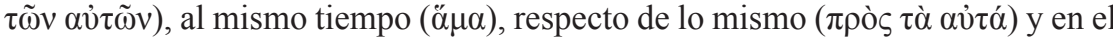

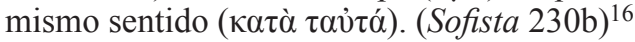

No estoy innovando al proponer que es la refutación socrática tal como es retratada en la obra temprana de Platón la práctica aludida por esta definición. ${ }^{17} \mathrm{Me}$ interesa resaltar de ella dos cuestiones: por un lado, que la sofística se lleva a cabo en un terreno argumentativo muy próximo al de la refutación; por otro, que la caracterización de la contradicción a la que se arriba aquí contrasta fuertemente con la de la sofística. Si la refutación elimina

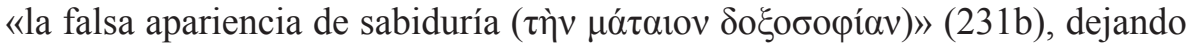
al alma del interlocutor pura para adquirir conocimientos, la sofística es su reverso casi perfecto: en tanto imitador del sabio, el sofista busca producir en sí mismo tal apariencia a partir de refutar solo de modo aparente las opiniones del interrogado.

Si bien el sofista de noble linaje no constituye la caracterización del filósofo que resulta del Sofista, ya que en $253 \mathrm{c}$-e la filosofía se identificada con la dialéctica $(\delta 1 \alpha \lambda \varepsilon \kappa \tau \iota \kappa \eta ́)$, ciencia $(\dot{\varepsilon} \pi \imath \sigma \tau \eta ́ \mu \eta)$ capaz de establecer la correcta comunicación entre las Formas, su inclusión entre la quinta y la séptima definición permite realizar una adecuada distinción entre las modalidades que puede adquirir la antilógica. Al igual que en el Eutidemo, la denuncia contra la sofística necesita un contrapunto, siendo la labor de Sócrates la que ocupa ese lugar, quien, al menos de acuerdo con la sexta definición, buscaba realmente refutar a su interlocutor. Si el Eutidemo es todavía ambiguo respecto de dónde ubicar una actividad como la de Eutidemo y Dionisodoro, el Sofista es claro respecto de su destierro no sólo del ámbito filosófico, sino también del de la refutación.

16 Cordero (1988, p. 365) traduce menos recargado el final del pasaje: «los confrontan unos con otros y muestran que, respecto de las mismas cosas, y al mismo tiempo, sostienen afirmaciones contrarias».

17 Hay acuerdo casi unánime sobre la cuestión. Para un acercamiento actual al tema, Cf. Solana (2013). 


\section{REFERENCIAS BiBLIOGRÁFICAS}

BURNET, J. (1995): Platonis Opera I. Oxford: Oxford University Press.

CANTO, M. (1989): Platon. Euthydème. Paris: Flammarion.

CHANCE, T. (1992): Plato's Euthydemus: Analysis of What Is and Is Not Philosophy. Berkeley-Los Angeles, University of California Press.

CHANTRAINE, P. (1968): Dictionnaire Étymologique de la langue grecque. Histoire des mots. Paris: Klincksieck.

CLASSEN, C. J. (1979): «Aristotle's picture of the sophists». En G. B. Kerferd (Ed.). The Sophists and Their Legacy. Wiesbaden: Franz Steiner Verlag Gmbh, pp. 7-24.

CORDERO, N. (1988): Platón. Sofista. Madrid: Gredos.

CORNFORD, F. M. (1935): Plato's Theory of Knowledge. London: Routledge y Kegan Paul.

CROMBIE, I. M. (1963): An Examination of Plato's Doctrines. Vol. II. Routledge y Kegan Paul: Londres.

DENYER, N. (1991): Language, Thought and Falsehook in Ancient Greek Philosophy. Londres-New York: Routledge.

DORION, L. A. (1995): Aristote. Les réfutations sophistiques. Paris: Vrin.

DORION, L. A. (2000): «Euthydème et Dionysodore sont-ils des Mégariques?». En T. Robinson y L. Brisson (Eds.). Plato. Euthydemus, Lysis, Charmides. Proceedings of the V Symposium Platonicum. Sankt Augustin: Academia Verlag, pp. 35-50.

GARDELLA, M. (2013): «Conflictos socráticos en el Eutidemo: la crítica platónica a la dialéctica megárica». Argos. Revista de la Asociación Argentina de Estudios Clásicos 36, pp. 45-64.

GILL, C. (2000): «Protreptic and Dialectic in Plato's Euthydemus». En T. Robinson y L. Brisson (Eds.). Plato. Euthydemus, Lysis, Charmides. Proceedings of the V Symposium Platonicum. Sankt Augustin: Academia Verlag, pp. 133143.

GILL, M. L. (2006): «Models in Plato's Sophist and Statesman». Journal of the International Plato Society 6.

GROTE, G. (1850): History of Greece. Volume 8. Cambridge: Cambridge University Press.

GUTHRIE, W. K. C. (1969): A History of Greek Philosophy III. The Fifth-Century Enlightenment. Cambridge, Cambidge Universit Press.

HAWTREY, R. (1981): Commentary on Plato's Euthydemus. Philadelphia: American Philosophical Society.

HITCHCOCK, D. (2000): «The origin of professional eristic». En T. Robinson y L. Brisson (Eds.). Plato. Euthydemus, Lysis, Charmides. Proceedings of the V Symposium Platonicum. Sankt Augustin: Academia Verlag, pp. 59-67.

KERFERD, G. B. (1976): «The Image of Wise Man in Greece in the period befote Plato». En Bossier F., De Wachter, F., Ijsewijn J. et al (Eds.). Images of Man in Ancient and Medieval Thought. Leuven: Leuven University Press. 
KERFERD, G. B. (1981): The Sophistic Movement. Cambridge: Cambridge University Press.

MARCOS, G. E. (2000), «Las Falacias en torno a la Falsedad. Una lectura de Eutidemo 283e-286b a la Luz de la Solución del Sofista». En T. Robinson y L. Brisson (Eds.). Plato. Euthydemus, Lysis, Charmides. Proceedings of the V Symposium Platonicum. Sankt Augustin: Academia Verlag, pp. 144153.

MÁRSICO, C. y H. INVERSO (2012): Platón. Eutidemo. Buenos Aires: Losada.

MÉRIDIER, L. (1931): Platon: Ion, Ménexène, Euthydème. Paris: Les Belles Lettres.

NARCY, M. (1984): Le philosophe et son doublé. Un commentaire de l'Euthydème de Platon. Paris: Vrin.

NARCY, M. (2013): «Remarks on the First Five Definitions of the Sophist (Soph. 221c-235a)». En B. Bossi y T. Robinson (Eds.). Plato's Sophist revisited. Berlin: De Gruyter, pp. 57-70.

NEHAMAS, A. (1989): «Eristic, Antilogic, Sophistic, Dialectic: Plato’s Demarcation of Philosophy from Sophistry». History of Philosophy Quarterly 7(1), pp. 3-16.

NOTOMI, N. (1999): The Unity of Plato's Sophist. Cambridge: Cambridge University Press.

OSCANYAN, S. (1972): «Won Six Definitions of the Sophist: Soph. 221c-231e». The Philosophical Forum 4, pp. 174-254.

RAPPE, S. (2000): «Father of the Dogs? Tracking the Cynics in Plato's Euthydemus». Classical Philology 95(3), pp. 282-303.

RICKLESS, S. (2010): «Plato's definition(s) of sophistry». Ancient Philosophy 30(2), pp. 289-298.

ROWE, C. (2015): Plato. Theaetetus and Sophist. Cambridge: Cambridge University Press.

SAYRE, K. (2006): Metaphysics and Method in Plato's Statesman. Nueva York: Cambridge University Press.

SERMAMAGLOU-SOULMADI, G. (2014): Playful Philosophy and Serious Sophistry. Berlin-Boston: De Gruyter.

SOLANA, J. (2013): «Socrates and 'Noble' Sophistry (Sophist 226b-231c)». En B. Bossi y T. Robinson (Eds.). Plato's Sophist revisited. Berlin: De Gruyter, pp. 71-85.

SPRAGUE, R. (1972): The Older Sophists. Indianapolis: Hackett Publishing Company.

SPRAGUE, R. (2000): «The Euthydemus Revisited». En T. Robinson y L. Brisson (Eds.). Plato. Euthydemus, Lysis, Charmides. Proceedings of the $V$ Symposium Platonicum. Sankt Augustin: Academia Verlag, pp. 3-19.

VIGO, A. (2001): «Platón, en torno a las condiciones y la función del diálogo cooperativo». Tópicos 9 , pp. 5-41. 
Francisco Villar es Profesor de Filosofía en la Universidad de Buenos Aires.

\section{Lineas de Investigación:}

Problemas metodológicos en la primera mitad del siglo IV a. C., haciendo especial foco en la disputa entre Isócrates y los socráticos respecto de los fundamentos, métodos y fines de la actividad filosófica

Publicaciones recientes:

(2018): «Los argumentos dialécticos de Eubúlides de Mileto: el Mentiroso, el Sorites, el Velado y el Cornudo». Factotum n ${ }^{\circ} 19 ; 48-59$

(2019): «La crítica de Isócrates a los socráticos en Contra los sofistas y Encomio de Helena». Signos filosóficos vol. 21, nº 42; 8-35

Correo electrónico: villarfr@gmail.com 
